\title{
A Class of GABAergic Neurons in the Prefrontal Cortex Sends Long-Range Projections to the Nucleus Accumbens and Elicits Acute Avoidance Behavior
}

\author{
Anthony T. Lee, ${ }^{1,2,3}$ Daniel Vogt, ${ }^{1}$ ๑ John L. Rubenstein, ${ }^{1}$ and Vikaas S. Sohal ${ }^{1,2,3}$ \\ ${ }^{1}$ Department of Psychiatry, ${ }^{2}$ Center for Integrative Neuroscience, and ${ }^{3}$ Sloan-Swartz Center for Theoretical Neurobiology, University of California, San \\ Francisco, San Francisco, California 94143-0444
}

\begin{abstract}
GABAergic projections from the neocortex to subcortical structures have been poorly characterized. Using Dlxi12b-Cre mice, we found anatomical evidence for GABAergic neurons that project from the mouse medial prefrontal cortex (mPFC) to multiple subcortical targets. We used a combination of patch-clamp electrophysiology, optogenetics, and pharmacology to confirm that Dlxil2b-labeled projections from the MPFC to the nucleus accumbens (NAcc) release GABA and do not corelease glutamate. Furthermore, optogenetic stimulation of these GABAergic projections from mPFC to NAcc induces avoidance behavior in a real-time place preference task, suggesting that these long-range projecting GABAergic neurons can transmit aversive signals. Finally, we found evidence for heterogeneous histochemical and/or electrophysiological properties of long-range projecting GABAergic neurons in the mPFC. Some of these neurons were labeled in parvalbumin-Cre and vasoactive intestinal peptide-Cre mice. We also used a novel intersectional targeting strategy to label GABAergic neurons in the mPFC that project to NAcc and found that these neurons have fast-spiking properties and express parvalbumin. These results define possible functions and properties for a class of long-range projecting GABAergic neurons in the neocortex.
\end{abstract}

Key words: aversion; GABA; nucleus accumbens; optogenetics; prefrontal cortex

\section{Introduction}

Knowledge about GABAergic neurons in the neocortex that send long-range projections to other structures remains sparse. Anatomical studies using retrograde tracing and immunohistochemistry have estimated that, in mice, cats, and monkeys, $<1-10 \%$ of all neocortical GABAergic cells give rise to long-range projections (Peters et al., 1990; Tomioka et al., 2005; Tomioka and Rockland, 2007; Higo et al., 2009; Tamamaki and Tomioka, 2010). Neocortical long-range projecting GABAergic neurons appear to constitute a heterogeneous population based on histochemical markers [parvalbumin-expressing $\left(\mathrm{PV}^{+}\right)$, somatostatin-expressing $\left(\mathrm{SOM}^{+}\right)$, neuropeptide $\mathrm{Y}$-expressing $\left(\mathrm{NPY}^{+}\right)$, neuronal nitric oxide synthaseexpressing $\left(\mathrm{nNOS}^{+}\right), \mathrm{NADPH}^{+}$, and $\mathrm{M} 2 \mathrm{R}$-expressing] and morphology (Tomioka et al., 2005; Jinno et al., 2007; Higo et al., 2009). Previous studies have not examined possible physiological or behavioral functions for neocortical long-range GABAergic projection neurons, but their connectivity onto GABAergic neurons in

Received March 21, 2014; revised June 8, 2014; accepted June 24, 2014.

Author contributions: A.T.L., D.V., J.L.R., and V.S.S. designed research; A.T.L. and D.V. performed research; D.V. and J.L.R. contributed unpublished reagents/analytic tools; A.T.L. analyzed data; A.T.L. and V.S.S. wrote the paper.

This work was supported by the Staglin Family, the International Mental Health Research Organization, National Institute of Mental Health Grants R00MH085946 and R37MH049428 (J.L.R.), National Institutes of Health/Office of the Director Grant 1DP2MH100011, and National Institute of General Medical Sciences Medical Scientist Training Program Grant GM07618 (A.T.L.).

Correspondence should be addressed to Dr. Vikaas Sohal, University of California San Francisco, Box 0444, San Francisco, CA 94143-0444.E-mail: vikaas.sohal@ucsf.edu.

DOI:10.1523/JNEUROSCI.1157-14.2014

Copyright $\odot 2014$ the authors $\quad 0270-6474 / 14 / 3411519-07 \$ 15.00 / 0$ distant cortical regions suggests that they may synchronize oscillatory activity (Caputi et al., 2013).

Recent applications of optogenetics have advanced our understanding of GABAergic projection neurons in subcortical structures and the hippocampus. GABAergic neurons in the medial septum form reciprocal circuits with hippocampal GABAergic neurons, signaling salient sensory events and controlling hippocampal theta oscillations (Jinno et al., 2007; Hangya et al., 2009; Kaifosh et al., 2013). Additional modulation of rhythmic oscillations occurs via a bidirectional GABAergic circuit comprising the hippocampus and entorhinal cortex (Melzer et al., 2012; Caputi et al., 2013). GABAergic projections from the ventral tegmental area to the nucleus accumbens (NAcc) can enhance associative learning (Brown et al., 2012); similar projections also regulate striatal output (Tritsch et al., 2012).

"Top-down" control by the prefrontal cortex (PFC) can influence emotional valence and motivated actions, often by inhibiting innate "bottom-up" processing (Miller, 2000; Shin and Liberzon, 2010; Lammel et al., 2014). Thus, if subcortically projecting GABAergic neurons exist in the PFC, they would be well positioned to exert top-down inhibitory control on subcortical processes. Indeed, here we describe evidence for long-range projecting GABAergic neurons in the medial PFC ( $\mathrm{mPFC}$ ) and demonstrate that stimulation of their projections to NAcc elicits avoidance behavior.

\section{Materials and Methods}

All experiments were conducted in accordance with procedures established by the Administrative Panels on Laboratory Animal Care at the University of California, San Francisco. 
Cloning of viral constructs. To produce the inhibitory intersectional retrograde tracer, we introduced MluI and BamHI compatible sticky ends to the Dlxi12b-BG sequence with PCR. The AAV-EF1a-DIOChR2-EYFP (from Karl Deisseroth, Stanford University, Stanford, CA) was then cut with MluI/BamHI and ligated to the PCR insert to exchange the EF1a promoter for Dlxi12b-BG. Virus was packaged by University of North Carolina Vector Core with serotype AAV5.

Slice preparation. Slice preparation and intracellular recording followed our published protocol (Sohal and Huguenard, 2005). We cut 250 $\mu \mathrm{m}$ coronal slices from 8- to 11-week-old mice of either sex. ACSF contained the following (in $\mathrm{mm}$ ): $126 \mathrm{NaCl}, 26 \mathrm{NaHCO}_{3}, 2.5 \mathrm{KCl}, 1.25$ $\mathrm{NaH}_{2} \mathrm{PO}_{4}, 1 \mathrm{MgCl}_{2}, 2 \mathrm{CaCl}$, and 10 glucose. We used the following mouse lines: wild-type C57BL/6 mice (Charles River); B6;129P2Pvalbtm1(cre)Arbr/J (line 008069; The Jackson Laboratory); Viptm1(cre) Zjh/J (line 010908; The Jackson Laboratory); Ssttm2.1 (cre)Zjh/J (line 013044; The Jackson Laboratory); and $\mathrm{Tg}(\mathrm{I} 12 b-\mathrm{cre}) 1 \mathrm{Jlr}$.

Intracellular recording. We obtained somatic whole-cell patch recordings using a Multiclamp 700A (Molecular Devices) and differential contrast video microscopy on an upright microscope (BX51WI; Olympus). Patch electrodes (tip resistance, 2-6 M $\Omega$ ) were filled with the following (in mM): $130 \mathrm{~K}$-gluconate, $10 \mathrm{KCl}, 10 \mathrm{HEPES}, 10 \mathrm{EGTA}, 2 \mathrm{MgCl}, 2$ $\mathrm{MgATP}$, and $0.3 \mathrm{NaGTP}$ ( $\mathrm{pH}$ adjusted to 7.3 with $\mathrm{KOH}$ ). All recordings were at $32.5 \pm 1{ }^{\circ} \mathrm{C}$. Series resistance was usually $10-20 \mathrm{M} \Omega$, and experiments were discontinued above $30 \mathrm{M} \Omega$.

Injection of opsin-containing virus or retrograde tracers. For Credependent expression of channelrhodopsin 2 (ChR2) or enhanced yellow fluorescent protein (EFYP), we injected $600 \mathrm{nl}$ of a previously described adeno-associated virus (AAV) vector that drives Credependent expression of a ChR2-EFYP fusion protein via previously described procedures (Sohal et al., 2009). Before stimulating ChR2containing terminals in the NAcc, we first verified the absence of fluorescent soma in the field of view. Coordinates for injection into MPFC were as follows (in mm relative to bregma): 1.7 anteroposterior (AP), 0.3 mediolateral (ML), and -2.50 to 2.7 dorsoventral (DV). Cholera toxin subunit B-488 (CTb-488; Invitrogen) was injected as above with the following NAcc coordinates (in mm): 0.90 AP, 0.65 ML, and -4.75 DV. We waited 2-3 d after injecting CTb before preparing brains slices.

ChR2 stimulation. We stimulated ChR2 in neurons using $\sim 5 \mathrm{~mW}$ flashes of light generated by a Lambda DG-4 high-speed optical switch with a $300 \mathrm{~W}$ xenon lamp (Sutter Instruments) and an excitation filter set centered around $470 \mathrm{~nm}$, delivered through a $40 \times$ objective (Olympus).

Behavioral tests. For social and novel object exploration, a juvenile mouse ( $<4$ weeks) or $50 \mathrm{ml}$ Falcon tube cap, respectively, was placed with the experimental mouse in its home cage for $5 \mathrm{~min}$. Exploration time was scored by the duration of nose-juvenile or nose-object contacts, and the reviewer was blinded to the virus identity and laser condition.

Real-time place preference (RTPP) occurred during three 20 min sessions over $3 \mathrm{~d}$. On day 1 , mice were habituated to the two-chamber apparatus. On day 2, mice were placed into one chamber and its movement was tracked by Anymaze (Stoelting). On day 3, mice were placed in the chamber opposite to one that was randomly designated to trigger 20 $\mathrm{Hz}$ laser pulses ( $470 \mathrm{~nm}, 15-20 \mathrm{~mW}, 5 \mathrm{~ms}$ ) after entry. The sides of the stimulated chambers were counterbalanced across all mice, and the experimenter was blind to the injected virus (control vs ChR2).

Drug application. Drugs were dissolved in water [DL-AP-5, CGP35348 ( $p$-3-aminopropyl-p-diethoxymethyl phosphoric acid)] or dimethylsulfoxide [CNQX, gabazine (GBZ)] before being diluted in ACSF.

Immunohistochemistry. After patch clamp, slices were fixed in 4\% PFA for at least $1 \mathrm{~d}$. Primary antibody used was mouse monoclonal anti-PV (Millipore). Alexa Fluor 488 goat anti-mouse (Invitrogen) was first applied and then washed for at least $2 \mathrm{~d}$ before addition of CF405 monoclonal mouse anti-biotin (Biotium).

Statistical analysis. We used Student's $t$ tests to compare across conditions or $n$-way ANOVA unless noted otherwise. Error bars indicate \pm 1 SEM.

\section{Results}

To visualize candidate long-range GABAergic projections originating from the neocortex, we first injected a Dlxi12b-Cre mouse with AAV-DIO-ChR2-EYFP in the mPFC (Fig. 1A). Dlx1 (Distal-less homeobox 1) and $D l \times 2$ are expressed by developing GABAergic neurons as they mature and migrate out of the ganglionic eminences in embryonic mice and are expressed predominately, if not exclusively, by GABAergic neurons (Anderson et al., 1997; Marin and Rubenstein, 2003). Indeed, many studies have used Dlxi12b-Cre mice to selectively label GABAergic neurons (Potter et al., 2009; Flandin et al., 2011; Han et al., 2012; Arguello et al., 2013). More recently, our laboratory has used the Dlxi12b enhancer to selectively express mCherry or ChR2 in cortical GABAergic neurons (Lee et al., 2014).

To confirm that, as in previous studies, Dlxi12b-labeled neurons are GABAergic and not glutamatergic, we recorded optogenetically evoked synaptic responses $(470 \mathrm{~nm} ; 5 \mathrm{~ms} ; \sim 5 \mathrm{~mW} /$ $\mathrm{mm}^{2}$ ) from mPFC pyramidal neurons of Dlxi12b-Cre mice injected with AAV-DIO-ChR2-EYFP. Thus, we used patched pyramidal neurons as "biosensors" to detect neurotransmitters released by nearby Dlxi12b-labeled neurons (Fig. 1C). During voltage-clamp recordings at both -70 and $+10 \mathrm{mV}$, application of GBZ $(10 \mu \mathrm{M})$ plus CGP35348 (5 $\mu \mathrm{M})$ essentially abolished all optogenetically evoked synaptic currents (Fig. $1 C$; the small residual outward current in one recording at $-70 \mathrm{mV}$ presumably represents incompletely blocked $\mathrm{GABA}_{\mathrm{B}} \mathrm{R}$-mediated current). This confirms that no glutamatergic neurons were labeled in the mPFC of Dlxi12b-Cre mice.

\section{Dlxi12b-labeled fibers project from $\mathrm{mPFC}$ to distant subcortical brain regions}

Our injection site spanned the $\mathrm{mPFC}$, including the anterior cingulate, prelimbic, and infralimbic regions (Fig. $1 A$, left). Surprisingly, we observed labeled fibers several millimeters from the injection site within corpus callosum and subcortical structures, including dorsal striatum, ventral striatum (NAcc), claustrum, and basolateral amygdala (Fig. 1 $A, B$ ). Importantly, no labeled cell bodies were found in these distant sites, including fields of view that were directly adjacent to the injection site (Fig. $1 A$, middle).

\section{Dlxi12b-labeled projections to the NAcc release GABA but not glutamate}

Of the candidate regions identified as possible targets for longrange GABAergic projections by Figure 1, we decided to focus on projections to the NAcc, because its distance from the mPFC minimizes the probability of virus leakage. To determine whether long-range Dlxi12b-labeled projections from $\mathrm{mPFC}$ to NAcc release GABA and/or glutamate, Dlxi12b-Cre mice were injected with AAV-DIO-ChR2-EYFP in the mPFC. After waiting at least 4 weeks for expression, we made wholecell recordings from neurons within the NAcc shell in acute brain slices. We recorded in voltage clamp at $+10 \mathrm{mV}$ while stimulating ChR2-containing terminals with blue light (470 nm, $5 \mathrm{~Hz}, 5 \mathrm{~ms}, \sim 5 \mathrm{~mW}$; Fig. 2A). No ChR2-labeled cell bodies were observed within NAcc during any of our recordings (Fig. $2 B$ ). Light-evoked IPSCs were detected in 13 of 29 patched neurons within NAcc (average peak IPSC amplitude, $391 \pm 95$ $\mathrm{pA} ; n=13$ ). To confirm that these projections release GABA, in a subset of recordings, we bath applied glutamate receptor antagonists ( $10 \mu \mathrm{M}$ CNQX $+50 \mu \mathrm{M}$ AP-5), followed by GBZ $(10 \mu \mathrm{M})$. Whereas CNQX + AP-5 exerted inconsistent effects on light-evoked IPSCs, the addition of GBZ essentially abolished them, demonstrating that these outward currents were GABAergic (control, $521 \pm 160$ pA; CNQX + AP-5, $424 \pm 135$ $\mathrm{pA}$; GBZ + CNQX plus AP-5, $9.4 \pm 1.8 \mathrm{pA} ; t_{(6)}=1.84, p=$ 
A
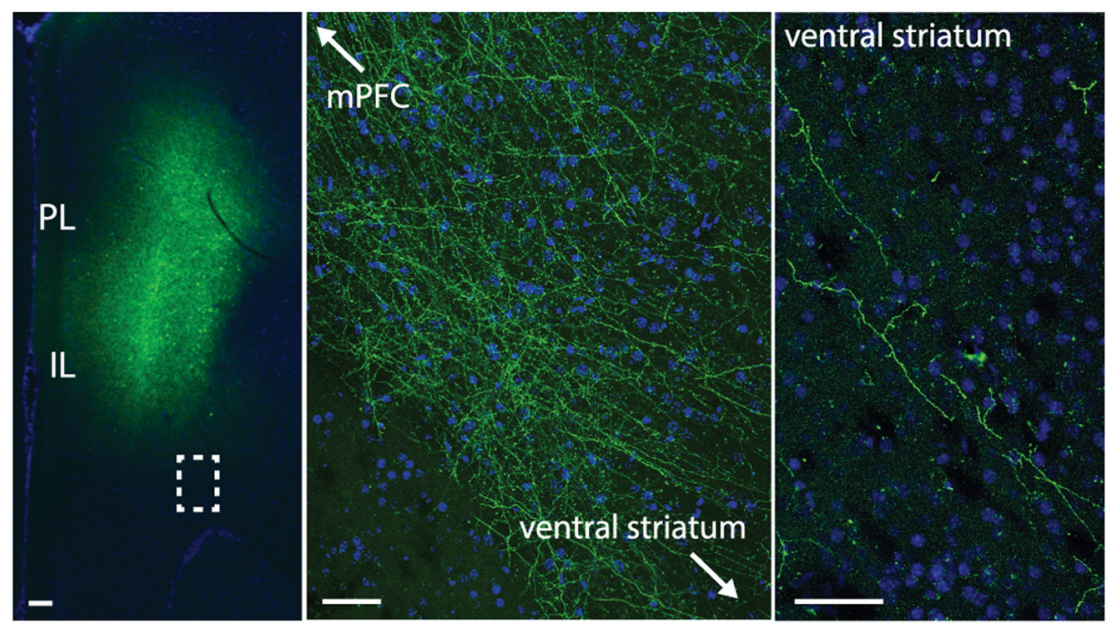

B
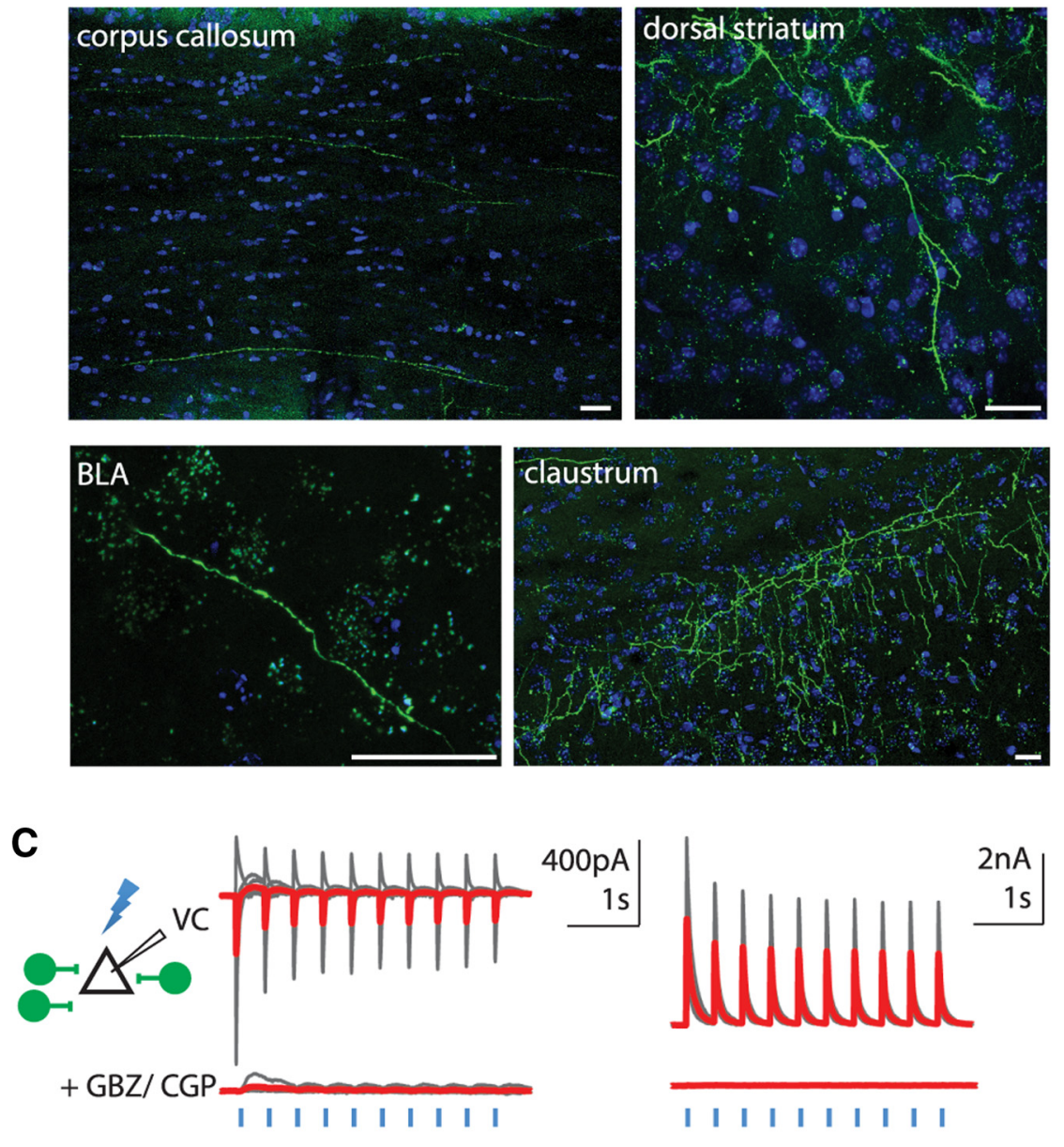

VC at $-70 m V$

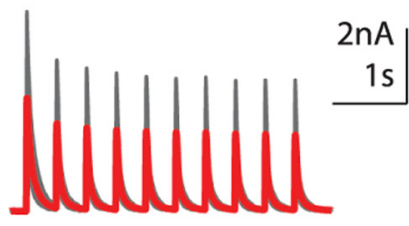

| | | | | | | | | | | |

VC at $+10 m V$

Figure 1. GABAergic neurons in the PFC project to subcortical targets. A, Left, AAV-DIO-ChR2-EYFP was injected into the cingulate, prelimbic (PL), and infralimbic (IL) cortices of $\mathrm{mPFC}$ in DIxi12b-Cre mice. Middle, Magnified view of the region of the left panel indicated by the dashed box. No labeled cell bodies were present in areas adjacent to the injection site, suggesting limited viral spread. Right, Dlxi12b-labeled fibers were found in ventral striatum. Scale bars, $50 \mu \mathrm{m} . \boldsymbol{B}$, Dlxi12b-labeled fibers from PFC are found in corpus callosum, dorsal striatum, claustrum, and basolateral amygdala (BLA). Scale bars, $30 \mu \mathrm{m}$. C, Dlxi12b-labeled cells are exclusively GABAergic. Left, Experimental design: we made voltage-clamp (VC) recordings from pyramidal cells (triangle) while optogenetically stimulating ChR2 ${ }^{+}$neurons (green) in D/xi12b-Cre mice injected with AAV-DI0-ChR2-EFYP. Right, Optogenetically evoked synaptic currents were abolished by GBZ + CGP35348 (CGP) ( $n=6$ pyramidal neurons).

0.12 for control vs CNQX + AP-5; $t_{(6)}=$ $3.19, p=0.02$ for control vs GBZ + $\mathrm{CNQX}+\mathrm{AP}-5 ; t_{(6)}=3.09, p=0.02$ for CNQX + AP-5 vs GBZ + CNQX + AP- $5 ; n=7$ cells; interaction by drug condition, $F_{(2,18)}=9.52, p=0.003$; Fig. $2 C, D)$. Furthermore, in separate experiments, GBZ alone abolished lightevoked currents recorded at either -70 or $+10 \mathrm{mV}$, demonstrating the absence of glutamate corelease (currents at -70 $\mathrm{mV}$ : control, $12 \pm 7 \mathrm{pA}$; GBZ, $2 \pm 1 \mathrm{pA}$; $F_{(1,6)}=8.21, p=0.001$; currents at +10 $\mathrm{mV}$ : control, $203 \pm 53 \mathrm{pA}$; GBZ, $12 \pm 4$ $\mathrm{pA} ; F_{(1,6)}=4.77, p=0.01 ; n=4$ cells; Fig. $2 E, F)$.

\section{Stimulating GABAergic projections from $m P F C$ to NAcc elicits avoidance behavior}

We hypothesized that stimulating longrange GABAergic inputs to NAcc would modulate motivational valence. To test this, we delivered optogenetic stimulation ( $470 \mathrm{~nm}, 20 \mathrm{~Hz}, 5 \mathrm{~ms}, 15-20 \mathrm{~mW} / \mathrm{mm}^{2}$ ) into the NAcc of Dlxi12b-Cre mice that had been injected at least 4 weeks earlier with AAV to drive Cre-dependent ChR2 expression in the mPFC (Fig. $3 A$ ). We measured the effects of this stimulation on behavior within a two-chamber RTPP task (Jennings et al., 2013; Fig. 3B). In the RTPP task, the two chambers are contextually identical and the stimulation occurs in real time, i.e., the light turns on whenever a mouse enters the designated stimulation chamber. Thus, in some ways, the RTPP task resembles self-stimulation more than conditioned place preference, and the RTPP task can be used to assay acute behavioral effects of stimulation. Importantly, mice do not exhibit an inherent place bias in the two-chamber RTPP task (Fig. 3F; time spent in placed side/total time: $0.50 \pm 0.03 ; t_{(18)}=0.009$, $p=0.99 ; n=19$ mice).

We habituated mice to the RTPP chambers on day 1 , measured the time spent in each chamber in the absence of stimulation on day 2 (baseline condition), and finally measured the time spent in each chamber in the presence of stimulation on day 3 (test condition). Compared with the baseline condition (day 2), mice spend significantly less time in the stimulated side on day 3 (test condition; Fig. 3C; fraction time spent in the stimulated side at baseline, $0.51 \pm 0.04$; in presence of stimulation, $0.29 \pm 0.04 ; t_{(9)}=4.246, p=$ $0.002 ; n=10$ mice). ChR2 ${ }^{+}$mice also spend less time on the stimulated side compared with control (ChR2-negative) mice that received light stimulation but 
A

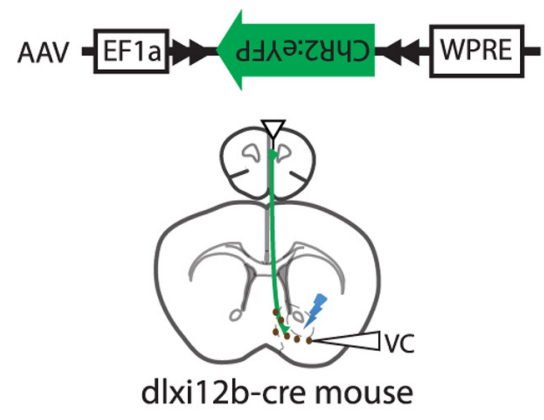

B

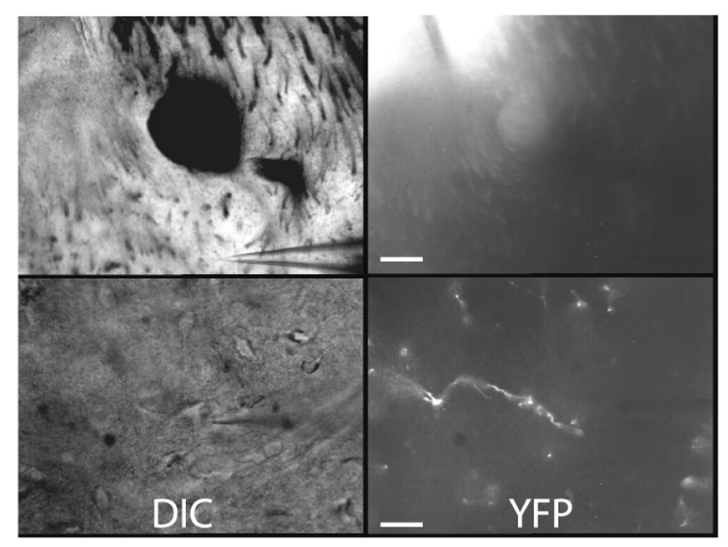

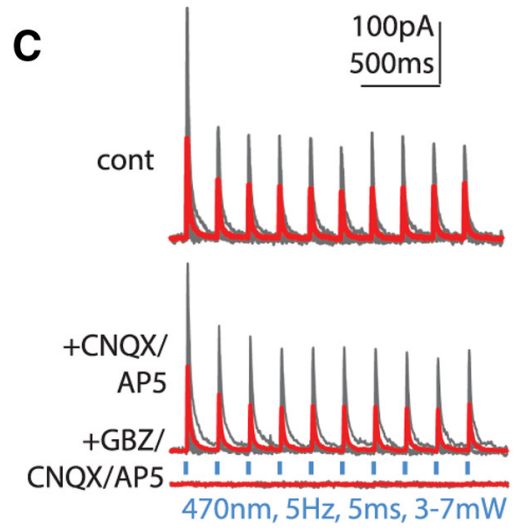

$\mathbf{E}$
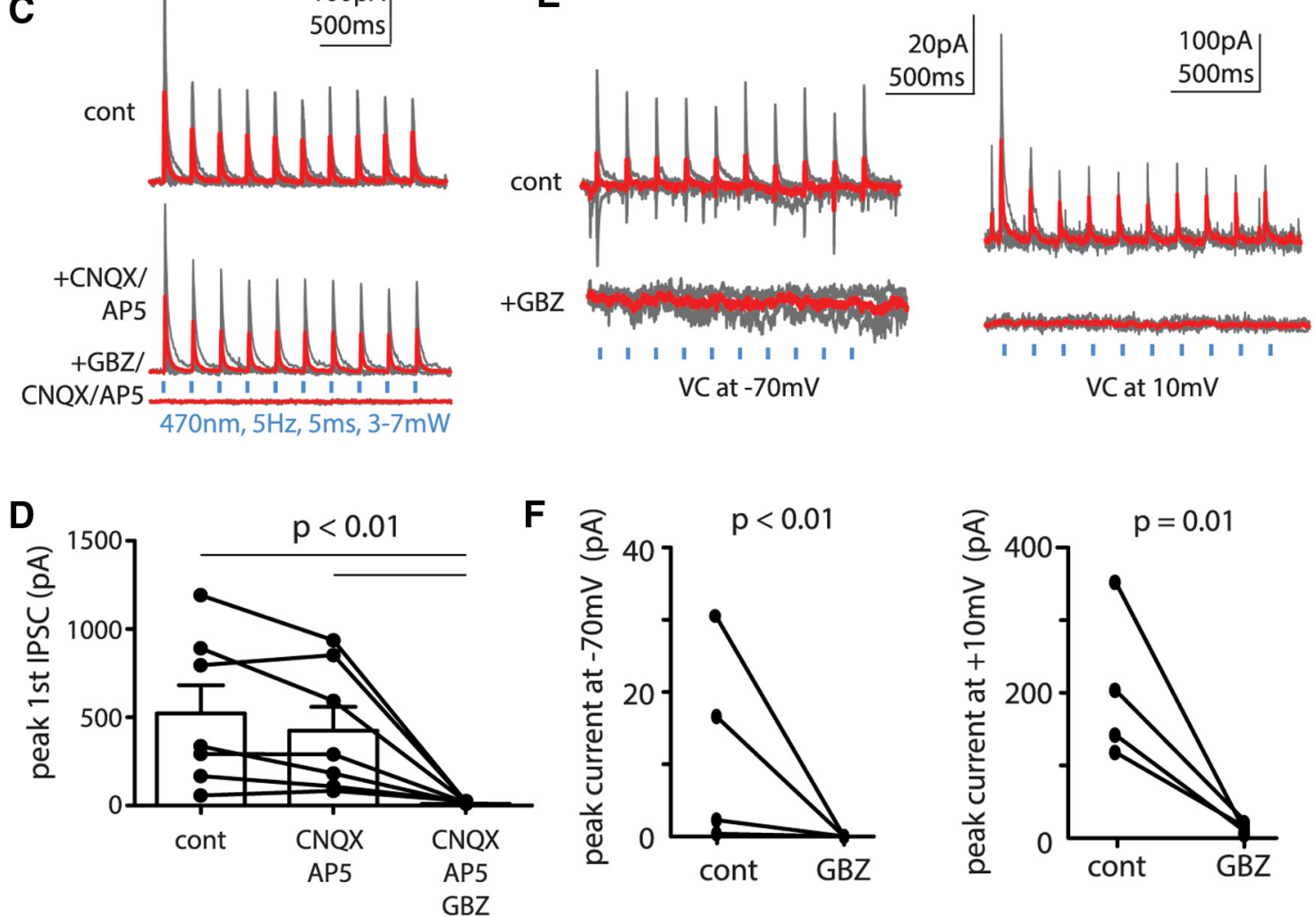

Figure 2. Dlxi12b-labeled PFC neurons projecting to ventral striatum exclusively release GABA. A, Experimental design: Dlxi12b-Cre mice were injected with AAV-DI0-ChR2-EYFP into the $\mathrm{mPFC}$. Recordings were made from NAcc neurons during optogenetic stimulation. $\boldsymbol{B}$, Images of ChR2 ${ }^{+} \mathrm{GABAergic}$ fibers projecting from mPFC within NAcc at low and high power (top and bottom rows; scale bars, 60 and $15 \mu \mathrm{m}$, respectively). $\boldsymbol{C}, \boldsymbol{D}$, Long-range Dlxi12b-labeled projections from mPFC release GABA. Light-evoked outward currents were inconsistently affected by CNQX/AP- 5 but completely blocked by adding GBZ ( $n=7$ cells). $E$, $F$, Dlxi12b-labeled fibers do not release glutamate because GBZ alone completely blocked currents recorded at -70 and $+10 \mathrm{mV}(n=4$ cells). cont, Control; DIC, differential interference contrast; VC, voltage clamp.

had been injected with either DIO-EYFP or Dlxi12b-mCherry viruses (control mice, $0.51 \pm 0.07 ; \mathrm{ChR} 2^{+}$mice, $0.29 \pm 0.04 ; t_{(14)}$ $=2.94, p=0.01 ; n=6$ and 10, respectively; Fig. 3D). We also computed the "difference score," which measures the difference between the time spent on the stimulated side on day 2 versus day 3. Again, $\mathrm{ChR} 2^{+}$mice that receive optogenetic stimulation of GABAergic projections from $\mathrm{mPFC}$ to NAcc spent significantly less time in the stimulated chamber on day 3 compared with the baseline condition on day $2\left(t_{(9)}=4.22, p=0.002\right)$. In contrast, there is no significant difference between time spent on the stimulated side on days 2 and 3 in control mice that lack ChR2 (for control mice compared with baseline, $t_{(5)}=0.857, p=0.43$; for a difference in the difference score between ChR2 ${ }^{+}$and control mice, $t_{(14)}=3.208, p=0.0063$; Fig. $\left.3 E\right)$. This acute avoidance behavior elicited by optogenetic stimulation does not appear to reflect changes in locomotion or anxiety, because testing using an open field did not reveal significant effects of stimulation on either the total distance traveled or time spent in the center of the open field (data not shown). NAcc terminal stimulation also had no effect on the time mice spend exploring a social target or novel object (data not shown); the former is particularly notable, because social exploration is sensitive to optogenetic stimulation within the mPFC (Yizhar et al., 2011). Together, these data demonstrate that long-range GABAergic projections from $\mathrm{mPFC}$ to NAcc modulate motivational valence and elicit acute avoidance behavior. 
A

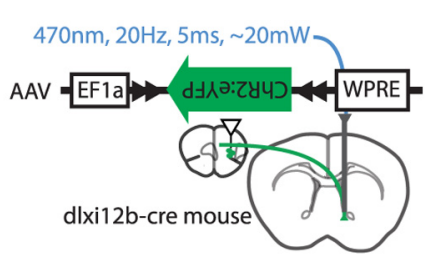

B

Day 1: habituation, $20 \mathrm{~min}$

Day 2: baseline, $20 \mathrm{~min}$

Day 3: test, 20 min, light stim

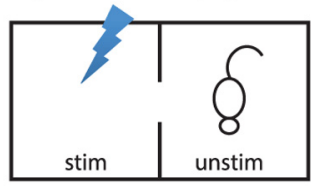

C

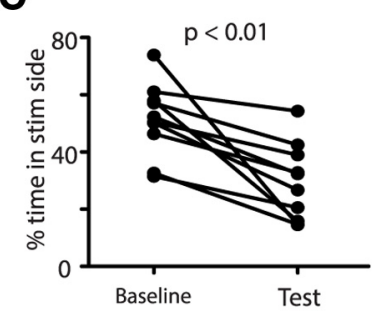

E

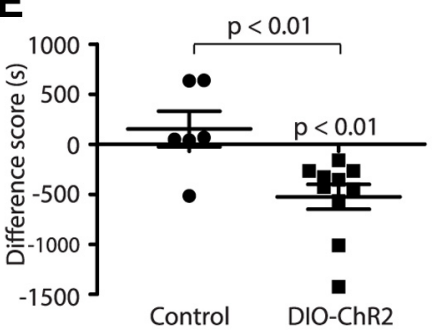

D

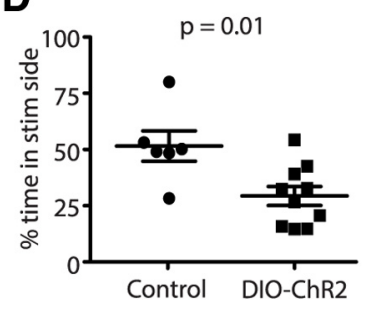

$\mathbf{F}$

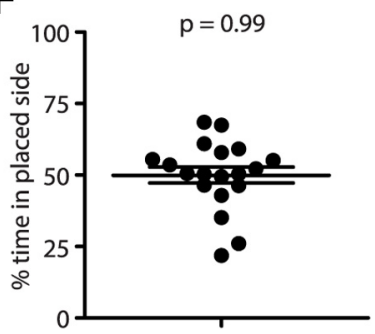

Figure 3. Stimulation of PFC GABAergic projections to NAcc elicits avoidance. $\boldsymbol{A}$, Experimental design: AAV-DI0-ChR2-EYFP was injected into mPFC of Dlxi12b-Cre mice, and optical fibers were implanted in the NAcc. $\boldsymbol{B}$, RTPP paradigm. Mice were placed into a two-chamber box for $3 \mathrm{~d}$. On the test day, one chamber triggered immediate light stimulation. $\boldsymbol{C}$, Mice spend less time in the stimulated side during activation of Dlxi12b-labeled mPFC-to-NAcc projections on the test day compared with baseline ( $p<0.01, n=10$ mice). $\boldsymbol{D}, \boldsymbol{E}$, Compared with control mice, DIxi12b-Cre mice injected with DI0-ChR2 spend less time in the stimulated side ( $p<$ 0.01). $\boldsymbol{F}$, Mice are not biased toward the placed side in the two-chamber RTPP task. Stim, Stimulated; Unstim, unstimulated.

\section{Properties of long-range projecting GABAergic neurons}

We next sought to determine whether at least some long-range projecting GABAergic neurons belong to well characterized classes of cortical GABAergic neurons. First, we crossed $P V-$ Cre, SOM-Cre, and VIP-Cre mice to a TdTomato reporter line (Ai14) and injected CTb-488 retrograde tracer (Invitrogen) into the NAcc (Fig. 4A,B). Colabeling was found in 6 of 144 and 5 of 100 TdTomato $^{+}$cells within the mPFC of $P V-C r e \times$ Ai14 and VIP-Cre $\times$ Ai14 mice, respectively (Fig. $4 A, B$ ); 0 of 156 colabeled cells were found SOM-Cre $\times$ Ai14 mice. Although the $P V-C r e$ and VIP-Cre lines both have greater than $\sim 90 \%$ specificity for labeling their respective classes of GABAergic neurons (Sohal et al., 2009; Taniguchi et al., 2011), it is possible that these labeled cells may not actually represent PV or vasoactive intestinal peptide (VIP) neurons ("false positives"). Conversely, these lines may not label all GABAergic neurons belonging to a particular histochemical class ("false negatives"). To at least partially address these concerns, we devised a viral strategy that combines intersectional genetics with retrograde tracing to label long-range projecting GABAergic neurons (Fig. $4 C$ ). We first replaced the EF1a promoter of an AAV-EF1a-DIO-ChR2-EYFP construct (Addgene) with the GABAergic neuron-specific Dlxi12b enhancer driving a minimal $\beta$-globin promoter. This AAV-Dlxi12b-DIOChR2-EYFP virus was injected into the mPFC, whereas AAV-

mCherry-IRES-WGA-Cre, which drives expression of a transynaptically transported Cre-recombinase fusion protein, was injected into the NAcc of C57BL/7 mice (Xu and Südhof, 2013). Because the Dlxi12b enhancer limits the expression of ChR2-EYFP to GABAergic neurons, only GABAergic neurons that are synaptically connected to the NAcc should be labeled by wheat-germ agglutinin (WGA), despite widespread Cre recombination of loxP/lox2272.

The five cells labeled with this intersectional retrograde tracing strategy all exhibited fast-spiking properties, as defined by narrow spikes (mean half-width, $0.42 \mathrm{~ms}$; range, $0.28-0.71 \mathrm{~ms}$ ) and minimal spike frequency adaptation (mean ratio of interstimulus interval 10/interstimulus interval 1, 1.05; range, 0.85-1.19; Fig. 4E,F). After fixing one of these brain slices, we found that five of seven neurons labeled by this intersectional retrograde tracing strategy, including two biocytin-filled fast-spiking neurons from which we had recorded, were $\mathrm{PV}^{+}$(Fig. 4G).

Of course, it is theoretically possible for WGA-Cre to traverse multiple synapses, labeling neurons that are disynaptically coupled to the injection site but do not project directly to it. However, WGA-Cre crosses each synapse with relatively low efficiency; thus, the fraction of labeling should be exponentially lower for polysynaptically connected neurons than for directly projecting ones. This fact, together with the observation that all five cells we patched had fast-spiking phenotypes, suggests that this phenotype is found among GABAergic neurons projecting directly to NAcc. Furthermore, the majority of cells labeled by our intersection approach resided in layer $2 / 3$ of mPFC (Fig. $4 A, D)$. In contrast, if significant polysynaptic spread had occurred, we would have expected to see additional labeled cells in layer 5 .

\section{Discussion}

We combined viral tracing methods, patch-clamp electrophysiology, and behavior with optogenetics to establish the existence, properties, and possible functions of long-range projecting GABAergic neurons in the neocortex.

Our initial attempts to identify known classes of cortical GABAergic neurons that contribute to long-range projections focused on $\mathrm{PV}^{+}, \mathrm{SOM}^{+}$, and $\mathrm{VIP}^{+}$neurons. Although these comprise $\sim 80 \%$ of cortical GABAergic neurons, other subtypes could also contribute to long-range projections (Rudy et al., 2011). In particular, some anatomical evidence suggest that a small population of $\mathrm{nNOS}^{+} / \mathrm{NPY}^{+}$neurons project callosally and subcortically (Tomioka et al., 2005; Tomioka and Rockland, 2007; Higo et al., 2009; Taniguchi et al., 2011). Similar to distinct classes of neocortical pyramidal neurons, additional subtypes of long-range projecting GABAergic neurons may target distinct subcortical structures (Shepherd, 2013).

We focused our study on long-range inhibition of the NAcc, because of its well appreciated role in reward seeking and motivated behavior. We find that long-range prefrontal inhibition of the NAcc results in acute avoidance behavior in an RTPP paradigm. Interestingly, this aversion occurs in the absence of previous contextual associations, suggesting that these long-range inhibitory projections may act to rapidly transmit aversive signals in parallel to, or in lieu of, conditioned associations. Of course, it is theoretically possible that stimulating projections within NAcc could elicit backpropagating action potentials that release GABA in other locations, contributing to the aversion we observed in the RTPP task. We consider such effects to be unlikely in light of the relatively 
A

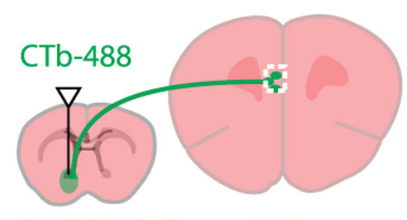

PV/SOM/VIP-cre; Ai14 mouse
B

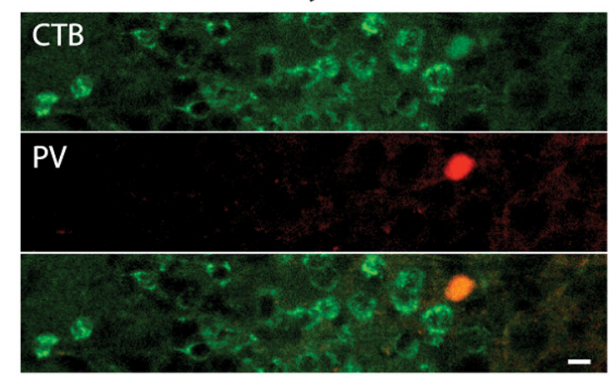

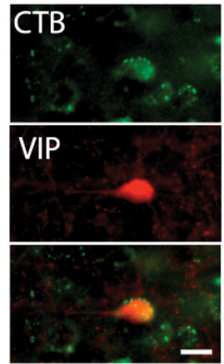

D

C
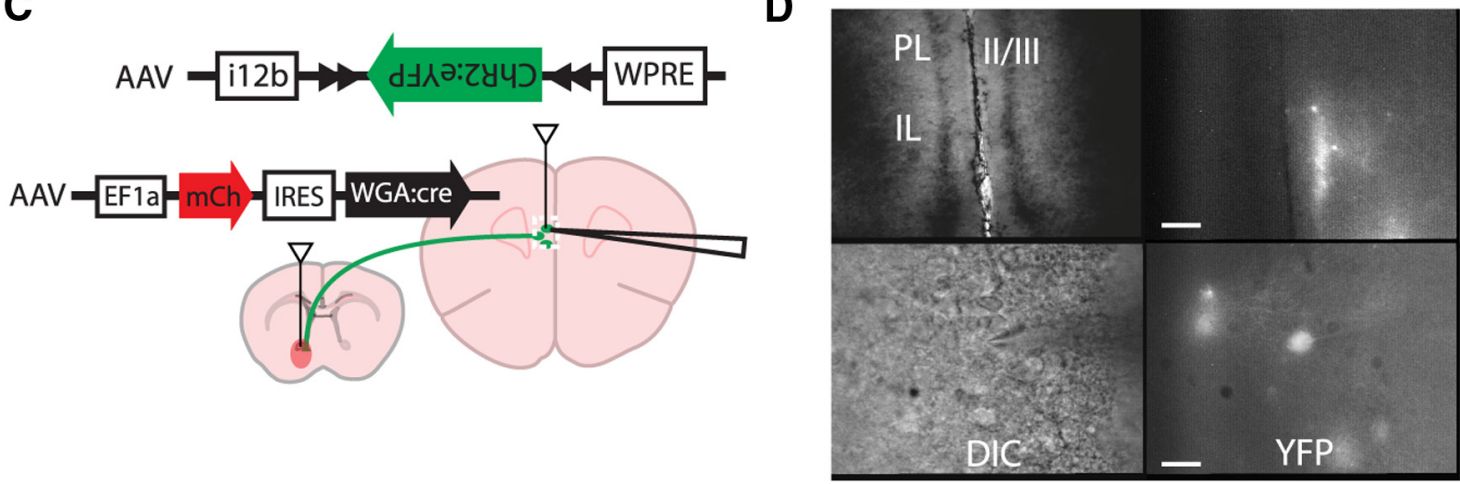

E

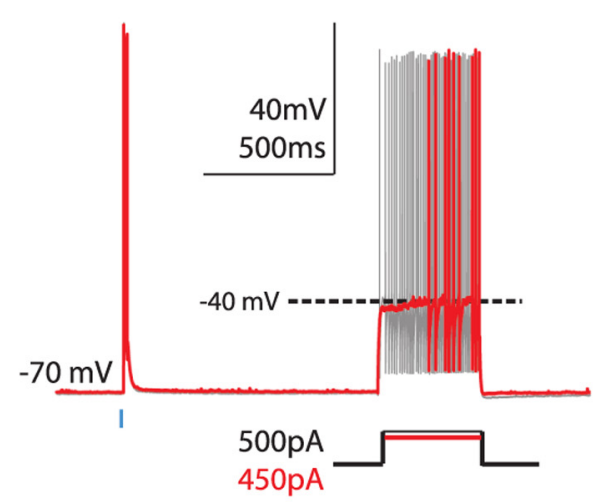

F

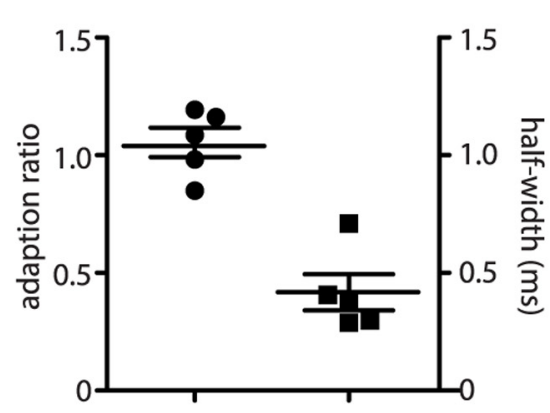

G

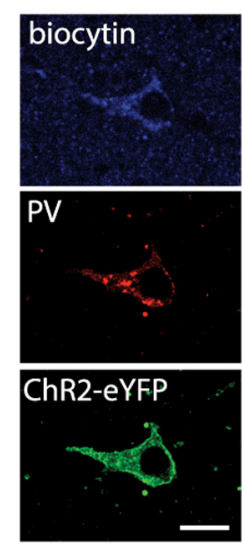

Figure 4. Long-range GABAergic projection neurons in PFC to NAcc are heterogeneous. $A$, Experimental design: the retrograde tracer CTb-488 was injected into the NAcc of $P V-C r e$, SOM-Cre, or VIP-Cre mice crossed with Ai14 mice. $\boldsymbol{B}$, PV-Cre- and VIP-Cre-labeled neurons in mPFC (red) colabel with the retrograde tracer (green) (scale bars, $15 \mu \mathrm{m}$ ). $\boldsymbol{C}$, Experimental design of a transynaptic-intersectional GABAergic neuron marker: AAV-mCherry-IRES-WGA::Cre and AAV-Dlxi12b-DI0-ChR2-EYFP viruses were injected into NAcc and mPFC, respectively. D, Images of GABAergic neurons labeled by a transynaptic-intersectional GABAergic marker in layers 2/3 at low and high power (top and bottom rows; scale bars, 60 and $15 \mu \mathrm{m}$, respectively). $\boldsymbol{E}$, Cells labeled by the transynaptic-intersectional tracer were fast spiking. $\boldsymbol{F}$, The adaption ratios and action potential half-widths for cells labeled in $\boldsymbol{E}$. G, Transynaptically labeled cells stain for PV. Scale bar, $10 \mu \mathrm{m}$. DIC, differential interference contrast; IL, infralimbic cortex; PL, prelimbic cortex.

long distance between $\mathrm{mPFC}$ and NAcc and the absence of stimulation-induced effects on other behavioral assays that measure the function of the mPFC, dorsal striatum, and amygdala. Regardless of whether stimulation in the NAcc leads to GABA release elsewhere, our results clearly demonstrate that long-range projecting GABAergic neurons, despite being relatively small in number, can powerfully shape behavior.

Notably, we failed to observe effects of tonically stimulating long-range GABAergic projections to NAcc on social exploration. This may reflect (1) inadequate recruitment of $\mathrm{mPFC}-\mathrm{NAcc}$ GABAergic inputs attributable to unilateral stimulation, (2) a discrepancy between the effects of tonic versus phasic patterns of input (i.e., during RTPP, stimulation may be effectively phasic, because the mouse is free to move away from the stimulated chamber at any time), or (3) the absence of a role for PFC-NAcc
GABAergic projections in social exploration. Future experiments could use real-time stimulation of these projections during epochs of various behaviors, e.g., social interaction, to clarify potential ways in which these projections could modulate additional behaviors.

Together, we find evidence for long-range GABAergic projections from the mPFC to subcortical targets, including the NAcc. This mPFC-NAcc projection releases GABA but not glutamate and can elicit acute avoidance behavior. Our results suggest that these long-range projecting GABAergic neurons may comprise heterogeneous subpopulations: some are labeled in VIP-Cre mice, whereas others are fast spiking and express PV. Future studies may uncover additional subtypes of long-range projecting GABAergic neurons in the neocortex. 


\section{References}

Anderson SA, Eisenstat DD, Shi L, Rubenstein JL (1997) Interneuron migration from basal forebrain to neocortex: dependence on Dlx genes. Science 278:474-476. CrossRef Medline

Arguello A, Yang X, Vogt D, Stanco A, Rubenstein JL, Cheyette BN (2013) Dapper antagonist of catenin-1 cooperates with Dishevelled-1 during postsynaptic development in mouse forebrain GABAergic interneurons. PLoS One 8:e67679. CrossRef Medline

Brown MT, Tan KR, O'Connor EC, Nikonenko I, Muller D, Lüscher C (2012) Ventral tegmental area GABA projections pause accumbal cholinergic interneurons to enhance associative learning. Nature 492:452456. CrossRef Medline

Caputi A, Melzer S, Michael M, Monyer H (2013) The long and short of GABAergic neurons. Curr Opin Neurobiol 23:179-186. CrossRef Medline

Flandin P, Zhao Y, Vogt D, Jeong J, Long J, Potter G, Westphal H, Rubenstein JL (2011) Lhx6 and Lhx8 coordinately induce neuronal expression of Shh that controls the generation of interneuron progenitors. Neuron 70: 939-950. CrossRef Medline

Han S, Tai C, Westenbroek RE, Yu FH, Cheah CS, Potter GB, Rubenstein JL, Scheuer T, de la Iglesia HO, Catterall WA (2012) Autistic-like behaviour in Scnla $+/-$ mice and rescue by enhanced GABA-mediated neurotransmission. Nature 489:385-390. CrossRef Medline

Hangya B, Borhegyi Z, Szilágyi N, Freund TF, Varga V (2009) GABAergic neurons of the medial septum lead the hippocampal network during theta activity. J Neurosci 29:8094-8102. CrossRef Medline

Higo S, Akashi K, Sakimura K, Tamamaki N (2009) Subtypes of GABAergic neurons project axons in the neocortex. Front Neuroanat 3:25. CrossRef Medline

Jennings JH, Sparta DR, Stamatakis AM, Ung RL, Pleil KE, Kash TL, Stuber GD (2013) Distinct extended amygdala circuits for divergent motivational states. Nature 496:224-228. CrossRef Medline

Jinno S, Klausberger T, Marton LF, Dalezios Y, Roberts JD, Fuentealba P, Bushong EA, Henze D, Buzsáki G, Somogyi P (2007) Neuronal diversity in GABAergic long-range projections from the hippocampus. J Neurosci 27:8790-8804. CrossRef Medline

Kaifosh P, Lovett-Barron M, Turi GF, Reardon TR, Losonczy A (2013) Septo-hippocampal GABAergic signaling across multiple modalities in awake mice. Nat Neurosci 16:1182-1184. CrossRef Medline

Lammel S, Tye KM, Warden MR (2014) Progress in understanding mood disorders: optogenetic dissection of neural circuits. Genes Brain Behav 13:38-51. CrossRef Medline

Lee AT, Gee SM, Vogt D, Patel T, Rubenstein JL, Sohal VS (2014) Pyramidal neurons in prefrontal cortex receive subtype-specific forms of excitation and inhibition. Neuron 81:61-68. CrossRef Medline
Marín O, Rubenstein JL (2003) Cell migration in the forebrain. Annu Rev Neurosci 26:441-483. CrossRef Medline

Melzer S, Michael M, Caputi A, Eliava M, Fuchs EC, Whittington MA, Monyer H (2012) Long-range-projecting GABAergic neurons modulate inhibition in hippocampus and entorhinal cortex. Science 335:15061510. CrossRef Medline

Miller EK (2000) The prefrontal cortex and cognitive control. Nat Rev Neurosci 1:59-65. CrossRef Medline

Potter GB, Petryniak MA, Shevchenko E, McKinsey GL, Ekker M, Rubenstein JL (2009) Generation of Cre-transgenic mice using Dlx1/Dlx2 enhancers and their characterization in GABAergic interneurons. Mol Cell Neurosci 40:167-186. CrossRef Medline

Rudy B, Fishell G, Lee S, Hjerling-Leffler J (2011) Three groups of interneurons account for nearly $100 \%$ of neocortical GABAergic neurons. Dev Neurobiol 71:45-61. CrossRef Medline

Shepherd GM (2013) Corticostriatal connectivity and its role in disease. Nat Rev Neurosci 14:278-291. CrossRef Medline

Shin LM, Liberzon I (2010) The neurocircuitry of fear, stress, and anxiety disorders. Neuropsychopharmacology 35:169-191. CrossRef Medline

Sohal VS, Huguenard JR (2005) Inhibitory coupling specifically generates emergent gamma oscillations in diverse cell types. Proc Natl Acad Sci U S A 102:18638-18643. CrossRef Medline

Sohal VS, Zhang F, Yizhar O, Deisseroth K (2009) Parvalbumin neurons and gamma rhythms enhance cortical circuit performance. Nature 459: 698-702. CrossRef Medline

Taniguchi H, He M, Wu P, Kim S, Paik R, Sugino K, Kvitsiani D, Fu Y, Lu J, Lin Y, Miyoshi G, Shima Y, Fishell G, Nelson SB, Huang ZJ (2011) A resource of Cre driver lines for genetic targeting of GABAergic neurons in cerebral cortex. Neuron [Erratum (2011) 72:1091] 71:995-1013. CrossRef Medline

Tomioka R, Rockland KS (2007) Long-distance corticocortical GABAergic neurons in the adult monkey white and gray matter. J Comp Neurol 505:526-538. CrossRef Medline

Tomioka R, Okamoto K, Furuta T, Fujiyama F, Iwasato T, Yanagawa Y, Obata K, Kaneko T, Tamamaki N (2005) Demonstration of long-range GABAergic connections distributed throughout the mouse neocortex. Eur J Neurosci 21:1587-1600. CrossRef Medline

Tritsch NX, Ding JB, Sabatini BL (2012) Dopaminergic neurons inhibit striatal output through non-canonical release of GABA. Nature 490:262-266. CrossRef Medline

Xu W, Südhof TC (2013) A neural circuit for memory specificity and generalization. Science 339:1290-1295. CrossRef Medline

Yizhar O, Fenno LE, Prigge M, Schneider F, Davidson TJ, O'Shea DJ, Sohal VS, Goshen I, Finkelstein J, Paz JT, Stehfest K, Fudim R, Ramakrishnan C, Huguenard JR, Hegemann P, Deisseroth K (2011) Neocortical excitation/inhibition balance in information processing and social dysfunction. Nature 477:171-178. CrossRef Medline 